Int. J. Plant Sci. 169(3):339-347. 2008.

(c) 2008 by The University of Chicago. All rights reserved.

1058-5893/2008/16903-0002\$15.00 DOI: $10.1086 / 526466$

\title{
DELAYED SENESCENCE IN CAULIFLOWER TRANSFORMED WITH AN AUTOREGULATED ISOPENTENYL TRANSFERASE GENE
}

\author{
Kim-Hong Nguyen, ${ }^{*}$ Wilco Jordi, $†$ Kees Van Dun, $\neq$ Frank Schepers, $§$ Evert Davelaar, $†$ \\ Geert Stoopen, $†$ Philip J. Dix, ${ }^{1, *}$ and Eugene J. Kane*

\begin{abstract}
*Institute of Bioengineering and Agroecology, Biology Department, National University of Ireland, Maynooth, County Kildare, Ireland; tPlant Research International, P.O. Box 16, 6700AA Wageningen, The Netherlands; $¥$ Rijk Zwaan Breeding, le Kruisweg 9, 4693 RS Fijnaart, The Netherlands; and §Nunhems Netherlands, P.O. Box 4005, 6080AA Haelen, The Netherlands
\end{abstract}

\begin{abstract}
Cauliflower (Brassica oleracea var. botrytis) was transformed, using Agrobacterium tumefaciens, with an autoregulated isopentenyl transferase $(i p t)$ gene under the control of a senescence-associated gene promoter, $\mathrm{pSAG}_{12}$, isolated from Arabidopsis thaliana. The effect of introducing this chimeric construct on cytokinin (CK) content, chlorophyll retention, and plant morphology and development were investigated. A range of CK and chlorophyll contents was found among the individual primary transformants. Progeny were studied from one of the primary transformed lines that did not have elevated cytokinin content and was phenotypically similar to the parent line but displayed delayed leaf senescence. The $\mathrm{pSAG}_{12}$ :ipt gene was inherited in a Mendelian manner, and the effect of this gene on senescence-related parameters was observed in a number of the progeny. While the $\mathrm{pSAG}_{12}$ :ipt progeny did exhibit delayed leaf senescence, it was accompanied by undesirable agronomic traits, including less synchronous curd initiation, smaller curd size, and greater susceptibility to fungal infection.
\end{abstract}

Keywords: Brassica oleracea, cauliflower, cytokinins, isopentnyl adenine, zeatin.

\section{Introduction}

Leaf senescence is a clearly recognizable stage in plant development, the first visible sign of which is loss of chlorophyll (Gut et al. 1987). The process of leaf senescence is believed to play an important role in remobilization of nutrients, particularly carbon and nitrogen, to other parts of the plant (Smart 1994). Numerous factors are known to influence the onset of senescence, including irradiance, nutrient availability, environmental stresses, temperature, and phytohormones (Thomas and Stoddart 1980).

Cytokinins $(\mathrm{CKs})^{2}$ are one class of growth regulators that have been implicated in the regulation of plant senescence (Goldthwaite 1987). Three lines of evidence support a role for CKs in the onset of senescence: (1) exogenous application of CK to detached leaves results in delayed onset of leaf senescence (Richmond and Lang 1957), (2) endogenous CK contents are shown to decline as senescence proceeds (Van Staden et al. 1988), and (3) several studies reveal that plants transformed with the Agrobacterium-derived ipt gene encoding the CK biosynthesis enzyme isopentenyl transferase exhibit delayed onset of leaf senescence (Smart et al. 1991; Hewelt et al. 1994). However, it quickly emerged that careful regulation of expression of the ipt gene was required to avoid the abnormal development associated with high CK production (Hewelt et al. 1994). Subse-

\footnotetext{
${ }^{1}$ Author for correspondence; e-mail: phil.dix@nuim.ie.

2 Abbreviations used in this article include the following: GUS $=$ $\beta$-glucuronidase, IPAR $=$ isopentenyl adenine riboside equivalents, $i p t=$ isopentenyl transferase, $\mathrm{PCR}=$ polymerase chain reaction, $\mathrm{pSAG}_{12}=$ senescence-associated gene promoter, and $\mathrm{ZR}=$ zeatin riboside equivalents.
}

Manuscript received April 2007; revised manuscript received July 2007. quently, ipt gene expression was tailored to senescence through the use of the promoter $\left(\mathrm{pSAG}_{12}\right)$ isolated from a senescenceassociated cysteine proteinase gene in Arabidopsis thaliana (Lohman et al. 1994; Gepstein et al. 2003). Using this senescenceassociated promoter to drive the expression of $i p t$, it was possible to autoregulate the production of $\mathrm{CK}$ in transformed tobacco plants (Gan and Amasino 1995). The $\mathrm{pSAG}_{12}$ :ipt tobacco plants exhibited delayed onset of leaf senescence but, since CK levels were only transiently elevated, were otherwise normal in appearance, apart from elevated flower and seed production compared to the wild-type parent. Such a delay in the onset of senescence could be of value in vegetable crops where losses occur due to the rapid onset of senescence. However, it is necessary to be alert to possible undesirable effects of delayed senescence on overall photosynthetic assimilate prioritization in the whole plant; for example, another study with tobacco (Jordi et al. 2000) has revealed reduced photosynthetic rate in the young leaves of $\mathrm{pSAG}_{12}$ :ipt plants. These effects may influence the overall growth pattern and life cycle of the plant and need to be evaluated in different crops that vary in their morphology, life cycle, and harvested product. As part of such an evaluation, we explored the use of the $\mathrm{pSAG}_{12}: i p t$ gene to delay the onset of senescence in Brassica vegetables. Here we report the effect of $\mathrm{pSAG}_{12}$ :ipt expression on senescence in the cauliflower cultivar Arbon.

\section{Material and Methods}

\section{Plants}

Seedlings 5-7 d old from cauliflower Brassica oleracea var. botrytis cv. Arbon were used for transformation experiments. 

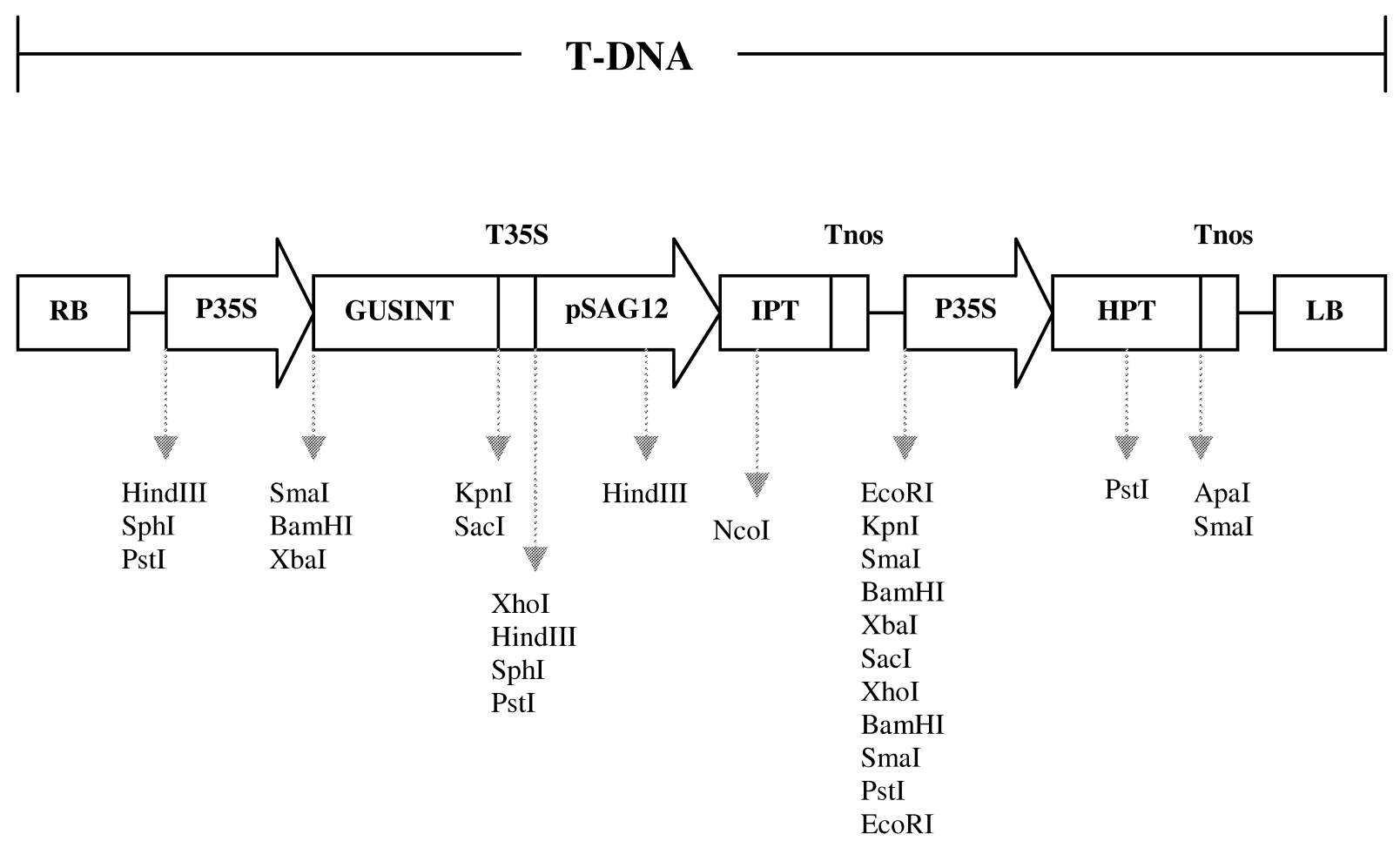

Fig. 1 Map of plasmid pVDH395 used for transformation of cauliflower cv. Arbon. LB = left border, Tnos = nopaline synthase terminator, $\mathrm{HPT}=$ hygromycin phosphotransferase, $\mathrm{P} 35 \mathrm{~S}=$ CaMV35S promoter, $\mathrm{IPT}=$ isopentenyl transferase, $\mathrm{pSAG} 12=$ promoter form $\mathrm{SAG}_{12}, \mathrm{~T}_{35 \mathrm{~S}}=$ CaMV35S terminator, and $\mathrm{RB}=$ right border.

Seeds were surface sterilized by soaking in $70 \%$ ethanol for $30 \mathrm{~s}$, given a 15 -min treatment with $20 \%$ Domestos (commercial disinfectant containing a detergent and with ca. $1 \%$ sodium hypochlorite as its active ingredient) solution, and washed three times with sterile distilled water. Ten to 15 seeds were then placed in tubs containing $25 \mathrm{~cm}^{3}$ growth medium $\left(4.6 \mathrm{~g} \mathrm{~L}^{-1}\right.$ Murashige and Skoog salts [Murashige and Skoog 1962] plus vitamins and $20 \mathrm{~g} \mathrm{~L}^{-1}$ sucrose, solidified with agar, $\mathrm{pH} 5.8$ ) and grown at $25^{\circ} \pm 1^{\circ} \mathrm{C}$ with a $16: 8$ photoperiod and irradiance of $60 \mu \mathrm{mol} \mathrm{m} \mathrm{m}^{-2} \mathrm{~s}^{-1}$. Hypocotyl segments were used as explants for transformation with Agrobacterium tumefaciens.

\section{Plasmid}

The Agrobacterium strain LBA 4404 harboring plasmid pVDH395 (fig. 1) was used for transformation. This plasmid's T-DNA cassette contains the $\mathrm{pSAG}_{12}$ :ipt gene, the selectable marker gene; hygromycin phosphotransferase $(h p t)$, conferring resistance to hygromycin; and the reporter gene (including an intron) encoding $\beta$-glucuronidase (GUSINT).

\section{Plant Transformation}

The Agrobacterium strain was grown overnight in liquid broth to reach a spectrophotometric absorbance $\left(\mathrm{A}_{600}\right)$ between 1.0 and 1.5 , and $0.15 \mathrm{~cm}^{3}$ of bacterial suspension was used to inoculate $20 \mathrm{~cm}^{3}$ of cocultivation medium $\left(3.2 \mathrm{~g} \mathrm{~L}^{-1} \mathrm{Gam}-\right.$ borg's B5 [Gamborg et al. 1968] plus vitamins, $20 \mathrm{~g} \mathrm{~L}^{-1} \mathrm{su}^{-}$ crose, $0.5 \mathrm{~g} \mathrm{~L}^{-1} \mathrm{MES}, 1.0 \mathrm{mg} \mathrm{L}^{-1}$ 2, 4-D, $1.0 \mathrm{mg} \mathrm{L}^{-1}$ kinetin, $\mathrm{pH}$ 5.8), in which the explants (100 hypocotyl segments, ca.
$10 \mathrm{~mm}$ in length) were cultured. Cocultivation was performed at $25^{\circ} \mathrm{C}$ with constant irradiance of $25 \mu \mathrm{mol} \mathrm{m} \mathrm{m}^{-2} \mathrm{~s}^{-1}$, and cultures were shaken at $40 \mathrm{rpm}$ for $2 \mathrm{~d}$. Cocultivation was stopped by addition of antibiotics to the medium $\left(500 \mathrm{mg} \mathrm{L}^{-3}\right.$ carbenicillin, $500 \mathrm{mg} \mathrm{L}^{-3}$ cefotaxime, and $200 \mathrm{mg} \mathrm{L}^{-3}$ vancomycin) for a further $24 \mathrm{~h}$ at $100 \mathrm{rpm}$. Explants were then removed from the cocultivation medium, blotted dry, and placed on regeneration medium (3.2 $\mathrm{g} \mathrm{L}^{-1}$ Gamborg's B5 plus vitamins, $30 \mathrm{~g} \mathrm{~L}^{-1}$ sucrose, $0.5 \mathrm{~g} \mathrm{~L}^{-1} \mathrm{MES}, 0.1 \mathrm{mg} \mathrm{L}^{-1} \mathrm{NAA}$, $1.0 \mathrm{mg} \mathrm{L}^{-1}$ BAP, pH 5.8, $500 \mathrm{mg} \mathrm{L}^{-1}$ carbenicillin, $10 \mathrm{mg} \mathrm{L}^{-1}$ silver nitrate, and $5 \mathrm{mg} \mathrm{L}^{-1}$ hygromycin) for selection of transformed plants. Cultures were transferred to fresh regeneration medium every $2 \mathrm{wk}$, and regenerated shoots were placed on rooting medium containing $10 \mathrm{mg} \mathrm{L}^{-1}$ hygromycin as the

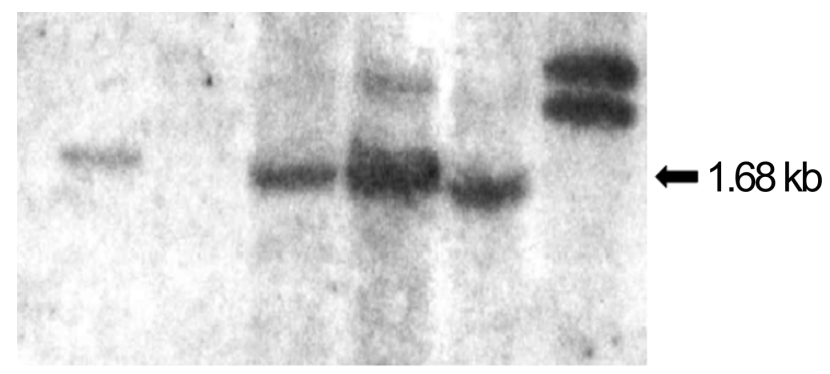

Fig. 2 Southern blot analysis of transgenic plants (EcoRI digest) with ipt gene probe. From left: lane 1, AS6; lane 2, negative control plant; lane 3, positive control plant; lane 4, AS1; lane 5, AS4; and lane 6 , ladder. The band is at $1.68 \mathrm{kB}$. 
selective agent. Shoots that survived hygromycin selection were tested to determine whether they were transformed.

\section{Polymerase Chain Reaction}

PCR was used to confirm the presence of ipt in primary transformants and their progeny. DNA was extracted from leaves as described by Frey (1998). To detect the ipt gene, two primers were designed to amplify a 395-bp fragment. The forward primer was 5'-TCAACCGGAAGCGGACGACC-3', and the reverse primer was 5'-TGGCTAGCAAACAACATGGC-3'. Reaction conditions for amplification of the target fragment included $1 \mathrm{mM} \mathrm{MgCl} 2,200 \mu \mathrm{M}$ dNTPs, and $200 \mathrm{nM}$ of each primer.

A

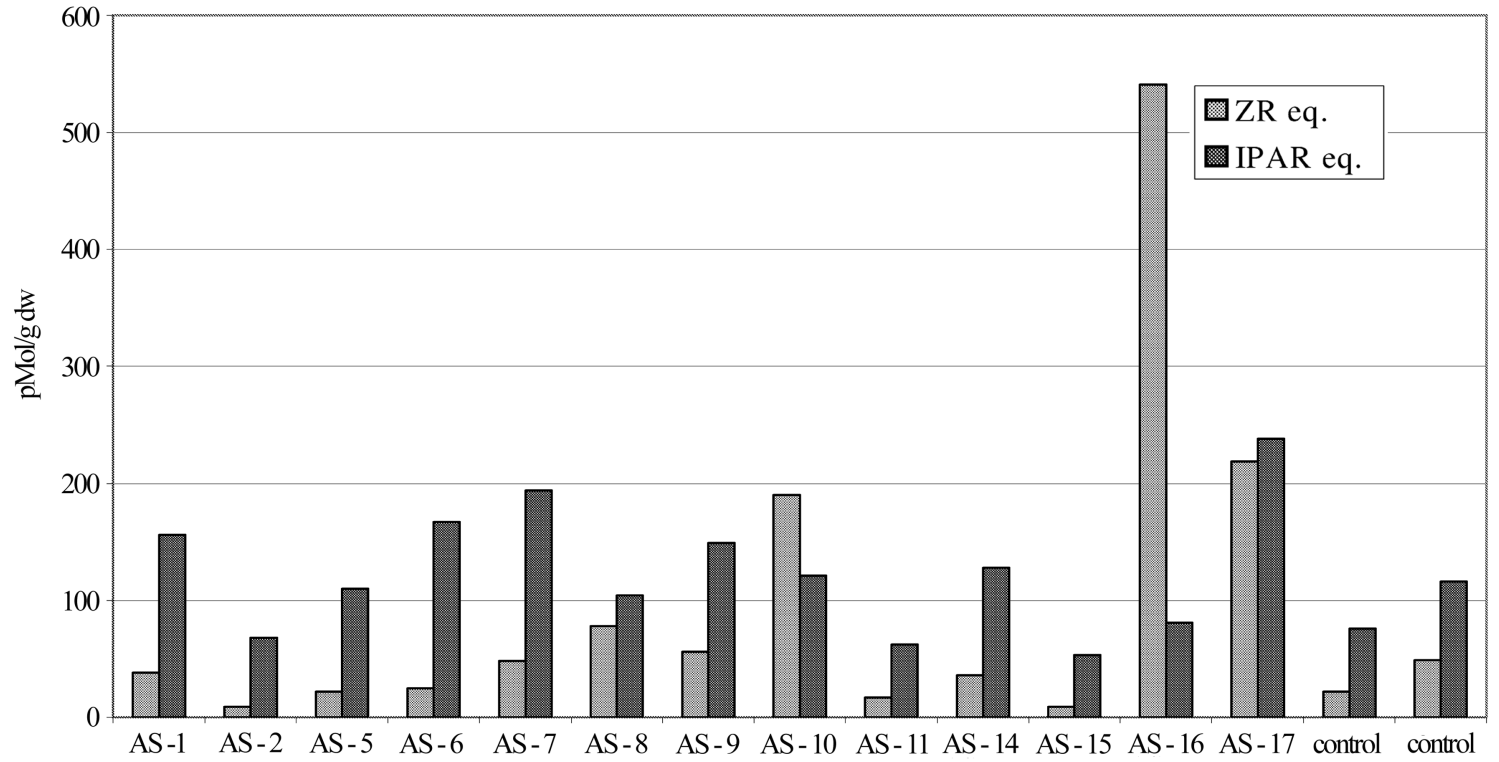

B

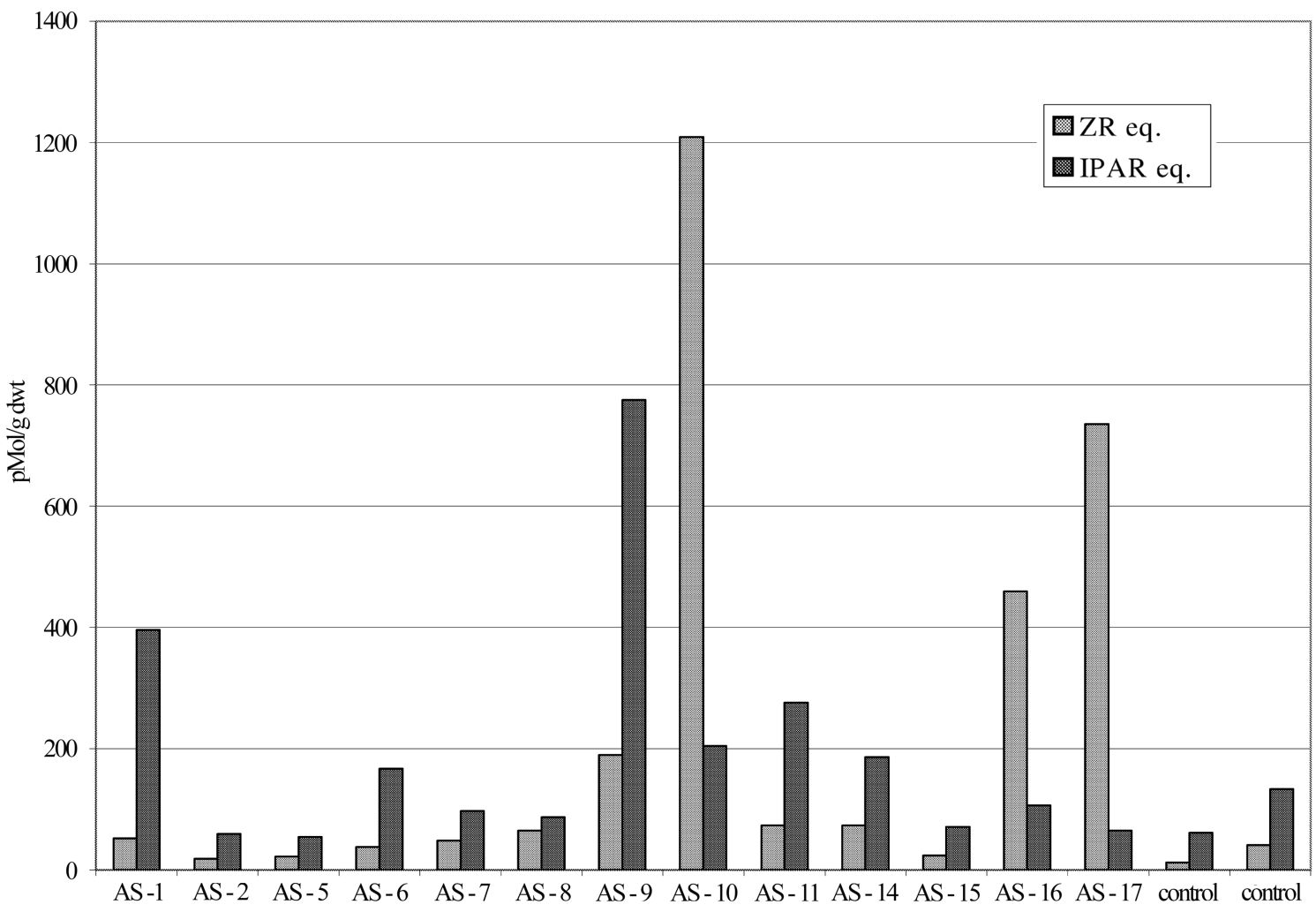

Fig. 3 Cytokinin contents $\left(\mathrm{pmol} \mathrm{g}^{-1} \mathrm{~L}\right)$ measured as isopentenyl adenine riboside equivalents (IPAR) and zeatin riboside equivalents (ZR) in young leaves $(A)$ and old leaves $(B)$ from cauliflower $\mathrm{cv}$. Arbon lines transformed with pSAG 12 :ipt. Plants were potted 9 wk before the leaves were sampled. Leaves were taken from single plants for each of the different transgenic lines tested. 
The cycle used was denaturation at $94^{\circ} \mathrm{C}$ for $5 \mathrm{~min}$ followed by 30 cycles of $94^{\circ} \mathrm{C}$ for $1 \mathrm{~min}, 60^{\circ} \mathrm{C}$ for $0.5 \mathrm{~min}$, and $72^{\circ} \mathrm{C}$ for $1 \mathrm{~min}$. PCR products were visualized by electrophoresis on $0.8 \%$ agarose gel stained with ethidium bromide.

\section{Southern Analysis}

Genomic DNA was extracted from leaf tissue following the method described by Frey (1998). DNA was digested with HindIII or EcoRI and after electrophoresis was blotted to a nylon filter. Detection was performed using a DIG-labeled, PCR-generated probe, following the method of McCabe et al. (1997). Ten micrograms of plant DNA was electrophoresed on $1 \%$ agarose in $1 \times$ TBE buffer at $30 \mathrm{~V}$ overnight. The gel was then denatured with $0.5 \mathrm{M} \mathrm{NaOH}$ and $1.5 \mathrm{M} \mathrm{NaCl}$ and neutralized with $0.5 \mathrm{M}$ Tris-HCL and $1.5 \mathrm{M} \mathrm{NaCl}$ solutions. The blotting was carried out on Hybond-N+ filter in $20 \times$ SSC overnight. The membrane was prehybridized and hybridized with the probe in DIG Easy Hyb solution at $42^{\circ} \mathrm{C}$. The first posthybridization and second washing for membrane were carried out with $2 \times$ SSC, $0.1 \% \times$ SDS at room temperature, and $0.1 \% \times$ SDS at $68^{\circ} \mathrm{C}$, respectively. Hybridization signals were detected by incubating the membrane in DIG-AP solution and $0.24 \mathrm{mM}$ 1,2-dioxetane chemiluminescent substrate and then exposing it to $\mathrm{x}$-ray film.

\section{Chlorophyll Content}

The chlorophyll content of leaves was determined using the method described by Roberts et al. (1990). Briefly, chlorophyll was extracted from leaf disks (10 $\mathrm{mm}$ diameter) by incubating each disk with $3 \mathrm{~cm}^{3}$ methanol for $2 \mathrm{~h}$ in the dark at $25^{\circ} \mathrm{C}$. The absorbance of $1 \mathrm{~cm}^{3}$ of the extract was determined at 650 and $665 \mathrm{~nm}$. Total chlorophyll per cubic centimeter of extract was calculated using the equation, total chlorophyll $=25.8$ $\mathrm{A}_{650}+4.0 \mathrm{~A}_{665}$.

\section{CK Analysis}

Leaves were taken from 9-wk-old greenhouse-grown plants. The "younger" and "older" leaves were the tenth and fifth leaves from the oldest node, respectively. The leaves were harvested and immediately frozen in liquid nitrogen before being freeze-dried. Extraction, purification, and quantification of CKs from the freeze-dried leaves were performed as previously described (Jordi et al. 2000). Samples were extracted in boiling ethanol. Ethanol was removed by evaporation under reduced pressure, and the aqueous residues were taken up in water. The separation of free and bound CKs was carried out by partitioning $(\mathrm{pH} 8.2)$ against water-saturated butan-1-ol (I). The water layer was treated with acid phosphatase $(\mathrm{pH} 6)$ and reextracted with water-saturated butan-1-ol (II). Butanol layers I and II, representing free and bound CKs, respectively, were evaporated to dryness. Purification of samples was achieved by a combination of anionic exchange and reverse-phase C18 column chromatography. Zeatine (Z), zeatin riboside (ZR), isopentenyl adenine (IPA), and IPA riboside (IPAR) were separated by HPLC, and CK quantification was carried out by an enzyme immunoassay using ZR and IPAR antibodies. For quantification of $\mathrm{CKs}$ as $\mathrm{ZR}$ equivalents (combined contents of $\mathrm{Z}, \mathrm{ZR}$, and bound $\mathrm{ZR}$ ) and IPAR equivalents (combined contents of IPA, IPAR, and bound IPAR), total samples were further treated with acid phosphatase and purified as above without the HPLC separation.
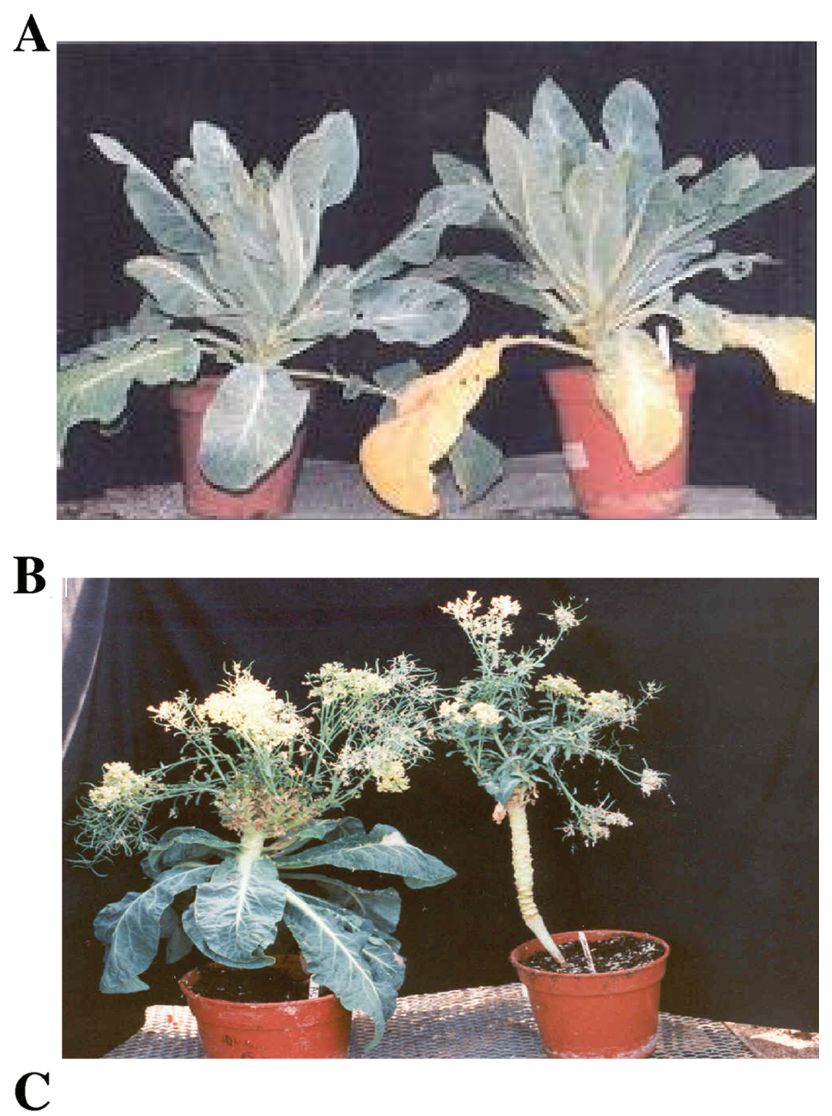

$\mathbf{C}$

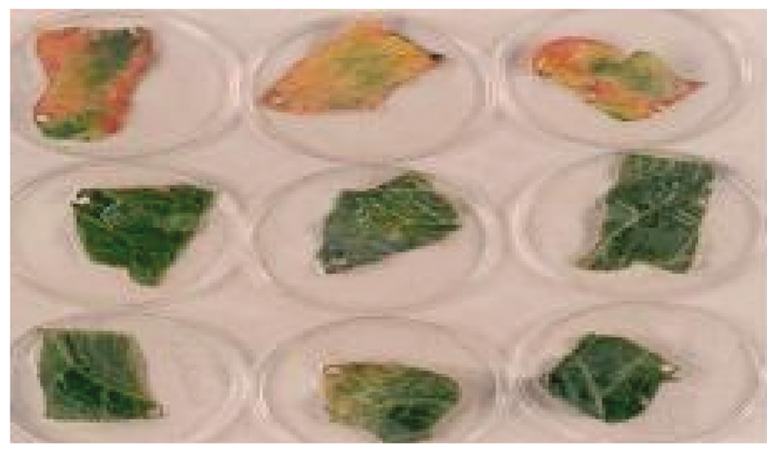

Fig. 4 A, Comparison of leaf senescence between transgenic line AS2 (left) and control Arbon (right). Plants grown in soil for $9 \mathrm{wk}$. Leaf senescence is clearly visible in the control, while the transgenic line has not started to senesce. $B$, Appearance of plants $1 \mathrm{yr}$ after transfer to soil. The leaves of transgenic plant AS2 were still green and attached (left). All the leaves had been lost from the control plant (right). C, Delayed senescence in detached leaves of transgenic plants. The detached leaves of the wild-type plant were kept in water and in zeatin riboside $(100 \mu \mathrm{M})$. The detached leaves of transgenic plants were kept in water only. Photographed at day 18 . From top: row 1 , the detached leaves of wild-type plant in water; row 2, detached leaves of wild-type plant in zeatin riboside $(100 \mu \mathrm{M})$; row 3, the detached leaves of transgenic plant AS5 in water. 


\section{Results}

\section{Selection and Identification of Transgenic Cauliflower}

Twenty-two resistant shoots were selected on regeneration medium with hygromycin, and regenerated shoots were rooted on medium containing hygromycin. All 22 plants survived on hygromycin rooting medium and were tested for the presence of the $\mathrm{pSAG}_{12}$ :ipt gene by PCR (data not shown). The gene was detected in 19 of the hygromycin-selected regenerants. The PCR data were confirmed by Southern analysis. The presence of the ipt gene was confirmed by probing the EcoRI digest (shown for some of the lines in fig. 2). Additional HindIII digestion was used to determine the number of inserts in 10 of the lines (data not shown). Only AS5 had a single insert. AS2, $3,4,11,15,18$, and 19 had two inserts, and AS14 and AS17 had three inserts.

\section{Analysis of Primary Transformants}

The objective was to identify a transformed line that showed tight control of ipt expression, i.e., with normal morphology, except for delayed leaf senescence, but without highly elevated CK levels. Detailed CK analysis could be carried out only on a limited number of plants, so it was decided to check a single plant from each of the transformants. The most promising line identified in this survey was then subjected to more rigorous analysis. CK contents were determined in younger or older leaves of wild-type cauliflower and in the equivalent leaves from the transgenic lines 9 wk after planting (fig. 3). At 9 wk, senescence was visible in the oldest leaves of the wild type (fig. $4 A$ ). The IPAR equivalents were generally more abundant in transformed and control plants than the zeatin-type CKs. The CK content was lower in the older leaves of controls, as expected, but many of the transgenic lines had more CKs in the older leaves than in the younger leaves. Higher CK contents were detected among the transformed lines, and some of the transgenic lines had greatly elevated CK content compared with the control (e.g., AS10; fig. 3). The plants with greatly elevated levels had aberrant morphology and in some cases very delayed onset of leaf senescence, suggesting that expression of the $i p t$ gene was not tightly regulated by $\mathrm{pSAG}_{12}$ in those plants. For example, high CK content in some plants (e.g., AS16 and AS17) resulted in reduction in plant height and leaf size, increased branching, and inhibition of root formation and growth (data not shown). The transgenic line AS10 was delayed in the initiation of curd and formed curd 5-6 wk later than the control plants. The ZR-equivalent-type CKs were the predominant form of CK detected in the plants with greatly elevated CK content (e.g., AS16, AS17, and AS10).

Some plants did have CK content close to that observed in the controls (e.g., AS2 and AS5; fig. 3). The morphology of these plants was similar to that of the control plants, with the exception of delayed leaf senescence (fig. 4A). The transgenic plants AS2 formed seeds normally, and green leaves were still on the plants $1 \mathrm{yr}$ after transfer to soil (fig. 4B). Curd formation began at the same time as the control in these transgenic lines.

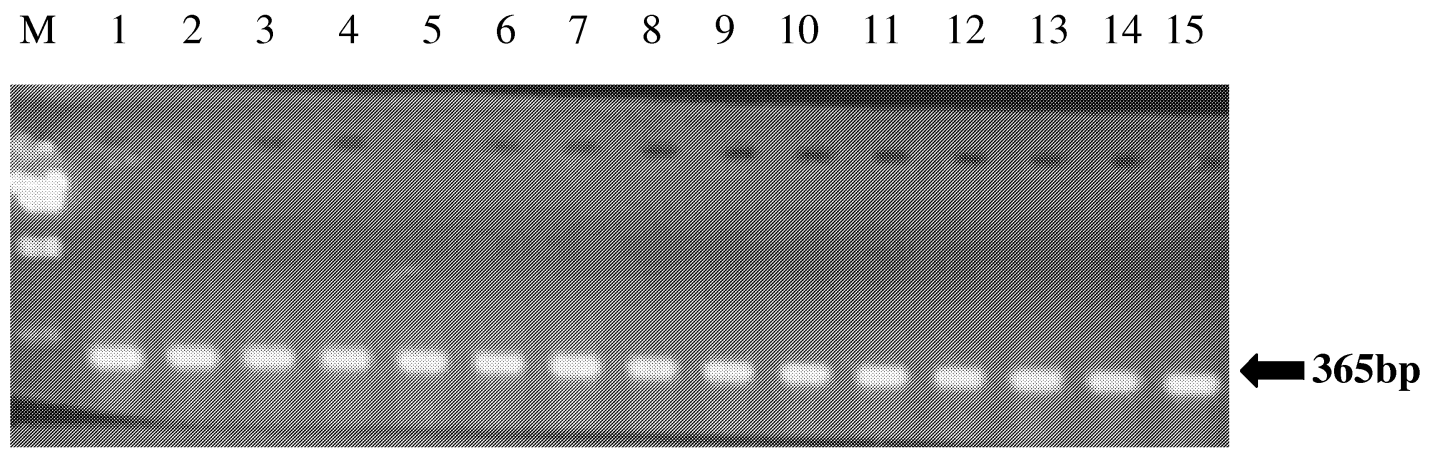

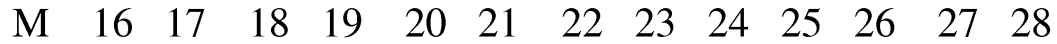

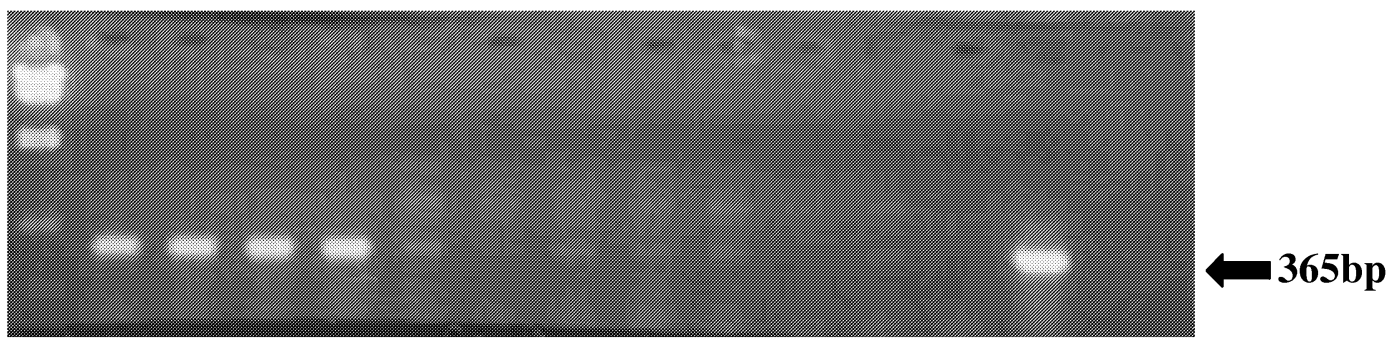

Fig. 5 PCR detection of the ipt gene in representative set from 50 progeny derived from a selfing of the primary transformant AS2. Lane M = molecular weight marker; 1-19 are $\beta$-glucuronidase (GUS)-positive progeny, 20-22 are GUS-negative progeny, 23-26 are control Arbon, 27 are water control, and 28 are plasmid pVDH395. The gene was detected in 47 of the 50 progeny tested, as indicated by the 365-bp band. No amplification was detected for the control and three of the progeny. All 47 plants that tested positive for ipt by PCR tested positive for GUS activity. 
The delayed senescence could also be demonstrated with excised leaf pieces (fig. 4C). The leaf senescence observed in Arbon leaf pieces is prevented by the inclusion of $\mathrm{CK}$ and is similarly apparent in these transgenic lines.

\section{Analysis of First-Generation Progeny}

A phenotypically normal line displaying delayed leaf senescence (AS2) was selected for further study. Seeds from the AS2

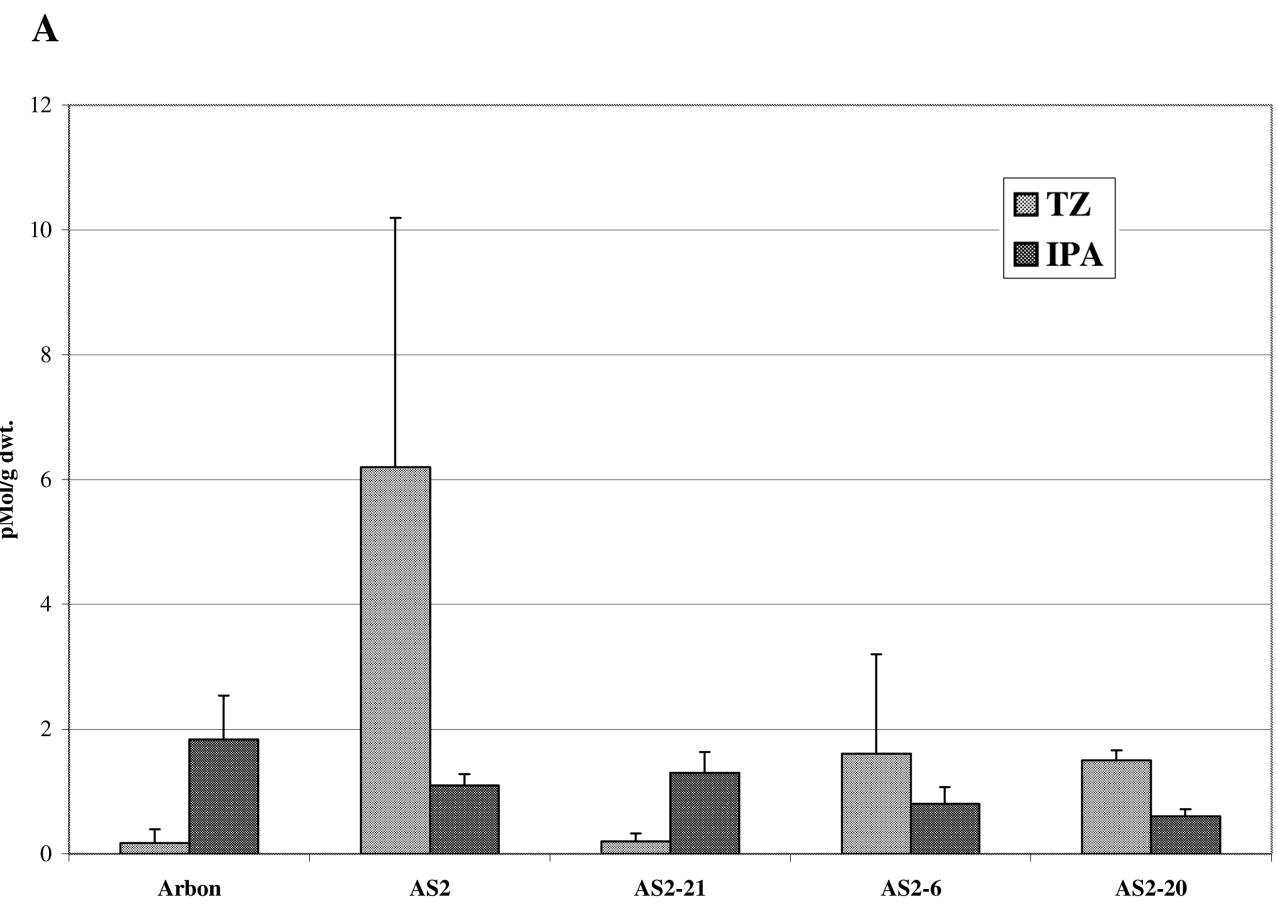

B

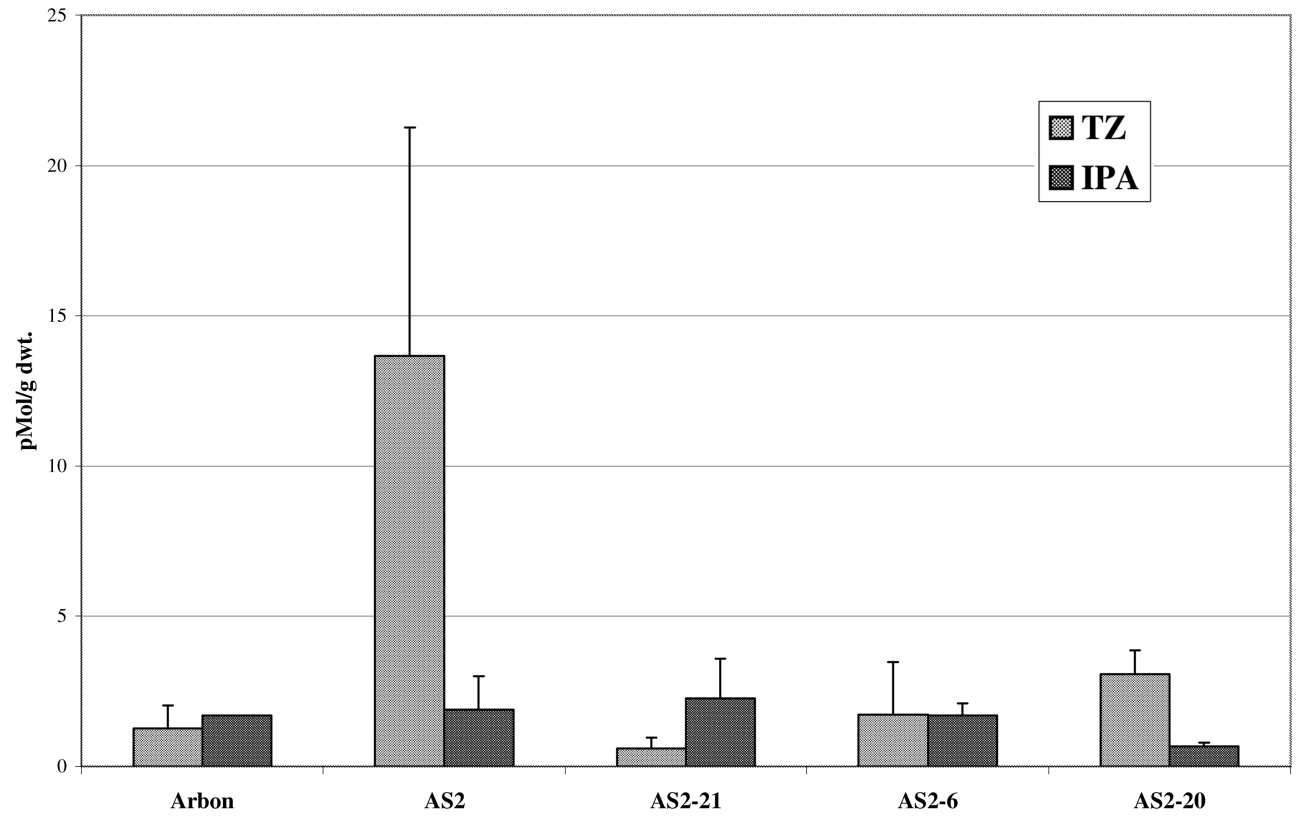

Fig. 6 Cytokinin levels in progeny of line AS2. Transzeatin and isopentenyl adenine cytokinin levels $\left(\mathrm{pmol} \mathrm{g}^{-1} \mathrm{~L}\right)$ measured in young leaves $(A)$ and old leaves $(B)$ of 9-10-wk-old plants of cauliflower cv. Arbon, primary pSAG 12 :ipt transformant AS2, azygous progeny AS2-21, ipt-positive progeny AS2 -6 with a single insert, and AS2 -20 with two insertions. $n=3$. 
Table 1

Chlorophyll Content in Leaf Disks from Primary Transformant AS2 and Its Progeny

\begin{tabular}{rrrrrc}
\hline Day & \multicolumn{1}{c}{ Arbon } & \multicolumn{1}{c}{ AS2 } & \multicolumn{1}{c}{ AS2-21 } & \multicolumn{1}{c}{ AS2-20 } & \multicolumn{1}{c}{ AS2-6 } \\
\hline 0 & $48.03 \pm 5.03$ & $48.53 \pm 7.08$ & $54.41 \pm 9.06$ & $55.46 \pm 1.55$ & $47.88 \pm 2.68$ \\
3 & $26.40 \pm 5.52$ & $31.56 \pm 3.13$ & $24.82 \pm 7.71$ & $38.63 \pm 4.60$ & $29.01 \pm 4.490$ \\
7 & $4.49 \pm 1.53$ & $14.89 \pm 6.45$ & $5.34 \pm 1.63$ & $19.38 \pm 7.73$ & $7.94 \pm 4.71$ \\
10 & $4.92 \pm 2.66$ & $12.98 \pm 6.63$ & $2.62 \pm 1.08$ & $9.75 \pm 8.28$ & $2.64 \pm .45$ \\
\hline
\end{tabular}

Note. Chlorophyll content $\left(\mathrm{mg} \mathrm{g}^{-1} \mathrm{~L}\right)$ measured in leaf disks from detached leaves of 9-10-wk-old plants of cauliflower cv. Arbon; primary pSAG 12 :ipt transformant AS2; azygous progeny AS2-21; ipt-positive progeny AS2-6, with a single insert; and AS2-20, with two insertions. Chlorophyll contents were measured four times following leaf detachment. Mean \pm SE, $n=6$.

line were grown, and progeny were tested for $\beta$-glucuronidase (GUS) activity and analyzed by PCR (fig. 5) for the presence of the ipt transgene. All ipt-positive plants were also GUS positive. A number of progeny were subjected to Southern analysis to determine the number of inserts in the PCR-positive plants, and CK levels were analyzed in their young and old leaves. Comparison between three progeny lines-AS2-21, an azygous line; AS2-6, a line with a single insert; and AS2-20, which had both inserts, the wild-type variety Arbon and primary transformant AS2-showed little difference in levels of transzeatin and isopentenyl adenine between the progeny plants and the control (fig. 6). However, the delayed senescence phenotype did segregate as expected, and the azygous line began to senesce at the same time as the wild type, while the progeny with either one or two insertions had delayed onset of leaf senescence, as observed in the primary transformant
AS2. Chlorophyll retention in leaf disks from detached leaves of the same set of plants was determined over a $10-\mathrm{d}$ period. The plants in which the transgene was detected had greater retention of chlorophyll than the azygous (AS2-21) and control plants up to day 7, and by day 10 there was still greater retention of chlorophyll in the primary transformant AS2 and the AS2-20 lines (table 1).

Time to curd initiation was also determined for a segregating population of AS2 progeny. The control plants initiated curd formation over a period of $3 \mathrm{wk}$, but there was a greater range in the time to curd formation in the progeny from the transgenic line. In the progeny from the transgenic AS2, curd initiation spanned a 12-wk period, beginning $5 \mathrm{wk}$ earlier than the control and ending 3 wk later. They produced smaller curds, sometimes showing an aberrant phenotype (fig. 7A, 7B). Curd diameter of the transgenic plants ranged between 50 and $150 \mathrm{~mm}$
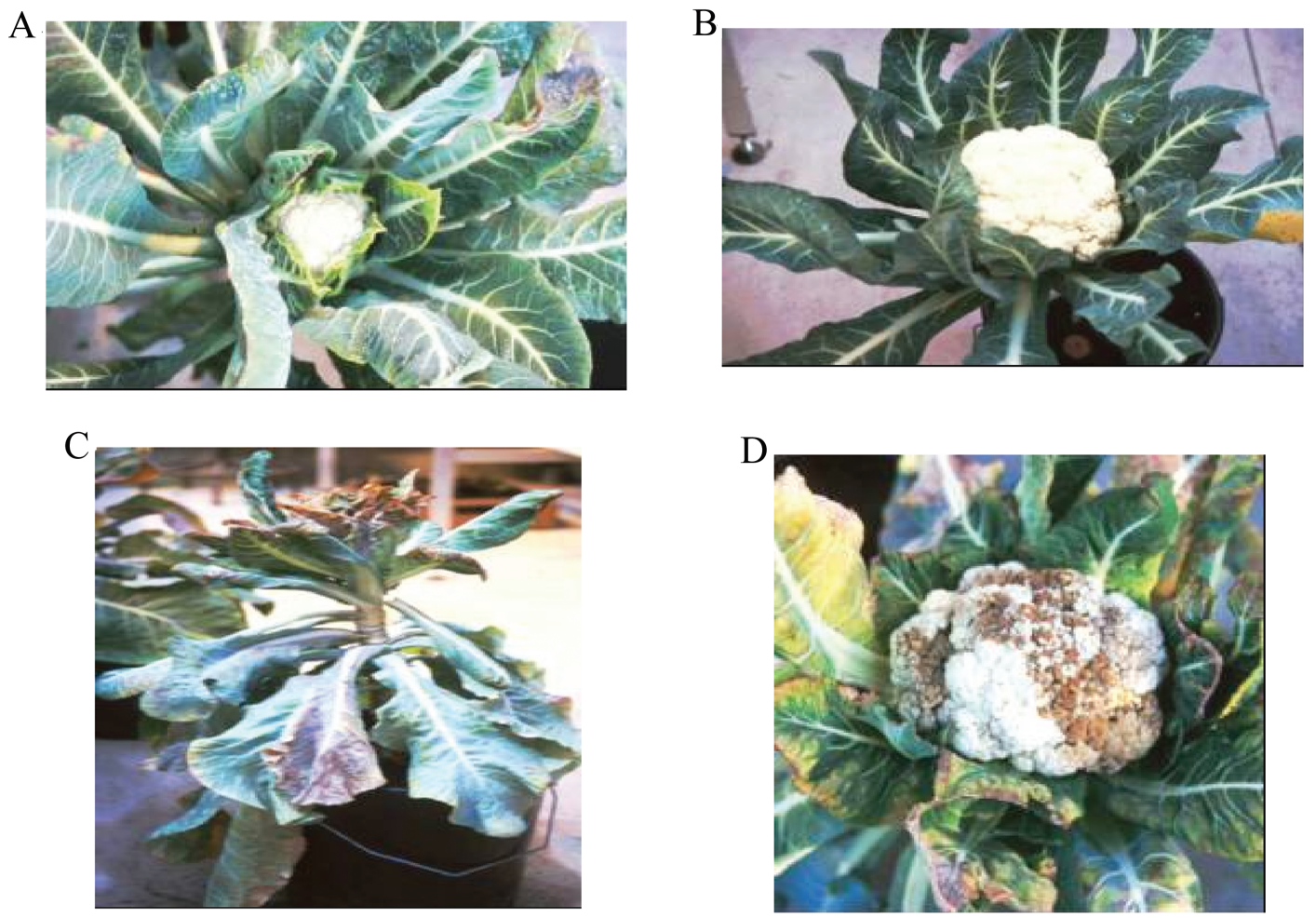

Fig. 7 Late developmental stages of greenhouse-grown plants. Curds of transgenic progeny from primary pSAG $12: i p t$ transformant AS2 $(A)$ tended to be smaller than those from equivalent Arbon plants $(B)$. Mature AS2 plants also suffered an increased incidence of leaf $(C)$ and curd $(D)$ damage, believed to be associated with fungal infection. 
and, for nontransgenic plants, between 110 and $200 \mathrm{~mm}$. The ipt gene thus had a negative effect on harvest index. The curds of the transgenic plants stayed firm, with a closed texture, for a longer time than on the controls. The control plants bolted earlier and were flowering earlier than transgenic plants. Transgenic plants showed a lower resistance to fungal infections like Botrytis (fig. 7C, 7D).

\section{Discussion}

The cauliflower cv. Arbon was successfully transformed with the $\mathrm{pSAG}_{12}$ :ipt gene, a construct previously used to delay leaf senescence in tobacco (Gan and Amasino 1995), lettuce (McCabe et al. 2001), broccoli (Chen et al. 2001), and petunia (Chang et al. 2003). We described how the pSAG ${ }_{12}$ :ipt is also effective in delaying the onset of leaf senescence in this important Brassica vegetable crop. Among the primary transformants analyzed, we found that the IPAR equivalents were higher than the ZR equivalents in most of the lines; this was also true for the control plants. Generally, the CK content was higher in the older leaves than in the young leaves of the transgenic plants. Comparison of the CK contents in young leaves of the transgenic lines with those from control plants showed higher CK content in some of the transgenic lines. It is possible that there is constitutive expression of $i p t$ in these plants or that there is transport of CK from the older leaves to the younger leaves, as was reported in young tobacco leaves from plants transformed with the $\mathrm{pSAG}_{12}$ :ipt construct (Jordi et al. 2000). In the tobacco study, ZR equivalents in young leaves were significantly elevated above the levels found in control plants, and it was postulated that this increase was due to activation of the $\mathrm{SAG}_{12}$ promoter under conditions of nutrient deficiency, resulting in localized production of $\mathrm{CK}$ in these younger tissues. Due to the strong sink activity of old leaves of $\mathrm{pSAG}_{12}$ :ipt tobacco plants under conditions of nutrient deficiency, remobilization of nutrients to young parts of the plant is blocked. This initiates senescence in young leaves and subsequently activates the $\mathrm{pSAG}_{12}$ promoter, which leads to elevated CK levels.

Importantly, there were some transgenic lines (e.g., AS2 and AS5) that exhibited delayed leaf senescence, had CK content similar to the control line, and were phenotypically normallooking plants. In these plants, the $\mathrm{pSAG}_{12}$ :ipt gene appears to be regulated in the senescence-specific manner and is autoregulated such that the CK contents are carefully controlled.

The analysis of specific CKs (isopentenyl adenine and transzeatin) in the primary transformant AS2 and three of its progeny showed that the levels of the biologically important CK isopentenyl adenine in the young and old leaves of the progeny lines tested were similar to those of control plants. The transzeatin levels of the $i p t$-positive progeny and primary transformant AS2 were elevated in both the young and old leaves compared to the level in the control and azygous progeny. This increased transzeatin level may exceed a proposed threshold level (Hewelt et al. 1994) and be sufficient to have a pronounced effect in delaying the onset of senescence.

When the ability of the selected progeny to retain chlorophyll was compared to that of the control and primary transformant AS2, it was clear that the azygous progeny behaved similarly to the control, while the ipt-positive plants retained a higher percentage of chlorophyll up to day 7 . It is notable that the progeny line in which only one copy of the gene was detected retained less chlorophyll than the line with two copies. This indicated that there may be a gene dosage effect supporting similar findings with hemizygous and homozygous tobacco plants transformed with $\mathrm{pSAG}_{12}$ :ipt (Jordi et al. 2000). A gene dosage effect was also noted in the first-generation progeny of $\mathrm{pSAG}_{12}$ :ipt-transformed lettuce, with the homozygous plants having greater delay in senescence than the hemizygotes (McCabe et al. 2001).

In a group of 45 progeny plants from primary transformant AS2, it was found that there was a wide variation in the time to curd formation. While cauliflower cv. Arbon plants all initiated curd formation over a 3-wk period, the progeny from the transgenic line initiated curd formation over an 11-wk period. Similarly, a change in time to bolting in broccoli transformed with pSAG $_{12}$ :ipt was reported, with some transformed lines bolting earlier and others later than the controls (Chen et al. 2001). It may therefore be possible to influence the time to curd formation in cauliflower by altering CK content and delaying leaf senescence in plants that are otherwise phenotypically normal. Based on our results, it is possible to recover $\mathrm{pSAG}_{12}: i p t$ transformed cauliflower plants that show heritable delayed leaf senescence characteristics while retaining the parental phenotype. However, the accompanying reduced curd size and greater susceptibility to fungal pathogens suggest that this alteration is unlikely to be economically viable. This assertion needs further evaluation, however, since Arbon is an $\mathrm{F}_{1}$ hybrid variety, and genetic segregation may contribute to the observed phenotypic variability. We are interested in further analyzing the effect of delayed senescence on the quality of the curd in $\mathrm{pSAG}_{12}: i p t$ transformed cauliflower.

\section{Acknowledgment}

This work was supported by European Commission grant FAIR-CT97-3161.

\section{Literature Cited}

Chang H, ML Jones, GM Banowetz, DG Clark 2003 Overproduction of cytokinins in petunia flowers transformed with $\mathrm{pSAG}_{12}: i p t$ delays corolla senescence and decreases sensitivity to ethylene. Plant Physiol 132:2174-2183.

Chen LFO, JY Hwang, YY Charng, CW Sun, SF Yang 2001 Transformation of broccoli (Brassica oleracea var. italica) with isopentenyltransferase gene via Agrobacterium tumefaciens for post-harvest yellowing retardation. Mol Breed 7:243-257.
Frey JE 1998 Genetic flexibility of plant chloroplasts. Nature 398:115-116. Gamborg OL, RA Miller, K Ojima 1968 Nutrient requirements of suspension cultures of soybean root cells. Exp Cell Res 50:151-158.

Gan S, RM Amasino 1995 Inhibition of leaf senescence by autoregulated production of cytokinin. Science 270:1986-1988.

Gepstein S, G Sabeli, M-J Carp, T Hajouj, M Falah, O Nesher, I Yariv, C Dor, M Bassani 2003 Large scale identification of leaf senescenceassociated genes. Plant J 36:629-642. 
Goldthwaite JJ 1987 Hormones in plant senescence. Pages 553-573 in PJ Davies, ed. Plant hormones and their role in plant growth and development. Nijhoff, Dordrecht.

Gut H, C Rutz, P Matile, H Thomas 1987 Leaf senescence in a nonyellowing mutant of Festuca pratensis: degradation of carotenoids. Physiol Plant 70:659-663.

Hewelt A, E Prinsen, J Schell, H Van Onckelen, T Schmulling 1994 Promoter tagging with a promoterless ipt gene leads to cytokinin-induced phenotypic variability in transgenic tobacco plants: implications of gene dosage effects. Plant J 6:879-891.

Jordi W, AHCM Schapendonk, E Davelaar, GM Stoopen, CS Pot, R de Visser, JA van Rhijn, S Gan, RM Amasino 2000 Increased cytokinin levels in transgenic Psag ${ }_{12}-I P T$ tobacco plants have large direct and indirect effects on leaf senescence, photosynthesis and $\mathrm{N}$ partitioning. Plant Cell Environ 23:279-289.

Lohman KN, S Gan, MC John, RM Amasino 1994 Molecular analysis of natural leaf senescence in Arabidopsis thaliana. Physiol Plant 92: 322-328.

McCabe MS, LC Garratt, F Schepers, WJRM Jordi, GM Stoopen, E Davelaar, JHA van Rhijn, JB Power, MR Davey 2001 Effects of Psag $_{12}$-IPT gene expression on development and senescence in transgenic lettuce. Plant Physiol 127:505-516.
McCabe MS, JB Power, AMM de Laat, MR Davey 1997 Detection of single-copy genes in DNA from transgenic plants by non-radioactive southern blot analysis. Mol Biotechnol 7:79-84.

Murashige T, F Skoog 1962 A revised medium for rapid growth and bioassay with tobacco tissue cultures. Physiol Plant 15:473-497.

Richmond AE, A Lang 1957 Effect of kinetin on protein content and survival of detached Xanthium leaves. Science 125:650-651.

Roberts AV, EF Smith, J Mottley 1990 The preparation of micropropagated plantlets for transfer to soil without acclimatization. Pages 227-236 in JW Pollard, JM Walker, eds. Methods in molecular biology. Vol 6. Plant cell tissue culture. Humana, Clifton, NJ.

Smart CM 1994 Gene expression during leaf senescence. New Phytol 126:419-448.

Smart CM, SR Scofield, MW Bevan, TA Dyer 1991 Delayed leaf senescence in tobacco plants transformed with $t m r$, a gene for cytokinin production in Agrobacterium. Plant Cell 3:647-656.

Thomas H, JL Stoddart 1980 Leaf senescence. Annu Rev Plant Physiol 31:83-111.

Van Staden J, EL Cook, LD Nooden 1988 Cytokinins and senescence. Pages 281-328 in LD Nooden, AC Leopold, eds. Senescence and aging in plants. Academic Press, San Diego, CA. 